\title{
Compendious research of Escrow Payment - Focusing on Future Considerations, Trends and Applications
}

\author{
Zohaab Ishrat
}

\begin{abstract}
The research on escrow payments given its future considerations, trends and applications indicated about it being a payment platform for the future. This can be attributed to be the result of its greater security and flexibility, in addition to the reduction of fraudulent activities. However, the digital payment systems must focus on the introduction of smartphone application, so that the consumers can make payments within a matter of minutes, rather than having them spend their valuable time on their websites to process their payments.
\end{abstract}

Index Terms - Digital Payment; Escrow Payment; Security; Virie Escrow.

\section{INTRODUCTION}

In the era of digitalisation, the conventional payment methods have been elbowed out of the market, and have been replaced by digital payment methods [1]. In particular, it has been identified that the credit unions and banks have now focused all their attention towards the digital payment strategies and trends, since these can potentially inform the financial service sector in terms of informing them about the commerce and its future [2]. The modern technology genesis has been expected to influence the ways in which payments are made, but an in-depth insight into these have further helped in identifying a series of trends that have not just chalenged the businesses, but have also influenced them into embracing more ingenious and efficient payment methods [3]. The purpose remains on the satisfaction of the csutomers, and their consistently advancing demands and needs in the contemporary era. By taking the aforementioned information into account, it is greatly important to focus on the future considerations, trends and applications of the digital payment in the form of escrow payment.

\section{LITERATURE REVIEW}

The contemporary landscape has brought some revolutionary changes in the digital payments, but what is more important is the trends that have been expected to change the face of banking and financial services sector, as identified and elaborated in the following sections;

\section{A. Trends of Digital Payments}

The digitalisation of the payment method has not yet been fully put into practice by the financial institutions, since this is not something that the appreciated by Generation Z [4]. However, these financial institutions have failed to recognise that the global consumers will be made of these overly ambitious and impatient consumers in the future. In particular, it has been identified that by 2020,40 per cent of the US consumers will be made of Generation Z, which makes this an emerging demographics trend. This generation has not yet experienced a world without internet connection or smartphone application, which means that they have not yet experienced manual payment [5]. In addition, a report by Accenture has shown that 80 per cent of the teenagers and young adults are more interested in giving up their traditional platforms and methods like TV and others for their smartphones. Furthermore, it has also been identified that 70 per cent of the Generation $\mathrm{Z}$ have dumped the traditional banking methods for agile and responsive payment methods [6].

The digitalisation has led to some prominent changes in the market, and one of the prominent trends indicate about the downgraded relevancy of the tangible banking systems like ATM cars as well as process payments [7]. This can be attributed to the rising demand for mobile application like Android Pay and Apple Pay, both of which have paved way for the biometric verifications; thereby clearly indicating about the future payments. This is the reason that more and more companies have shown significant attention towards upgrading their software, where the purpose is to ensure that biometric verifications can be used as the source of all payments [8]. Among this very trend, it has also been found that biometric technology has significantly advanced, which means that instead of just focusing on the facial recognition and finger prints, the focus has shifted more towards iris recognition as well as the heartbeat analysis. The purpose remains on offering security to the customers, especially when they are engaging in processing payments for different purposes. Another prominent reason that biometric has become a trend is embedded in its boosted efficiency, followed by accuracy and security [9].

The rising statistics of fraudulent activities, in the contemporary business landscape, has made banks and other financial institutions to outwit the ones engaging in such activities without losing its relevancy and ease of usage for the other consumers [10]. In this context, it has also been identified that security has become a central aspect when cross-border payments are taken into account, since this has eventually triggered the consumers, since they have been exposed to scammers, who would do anything to get their hands on the money for financial gains. With the latter into consideration, it has been estimated that the financial and banking industry would have lost approximately $\$ 31.3$ billion 
simply because of the loss of cards. This has eventually called for a more effective and innovative payment method like Bitcoin and Escrow system that can make it extremely difficult for the scammers and fraudsters to survive. Both of these systems are highly secured, and have special features in place to help in the validation of the payments by the consumers [11]. This makes these to be highly secured, which can further influence the customers into considering these platforms, when the consumers are in need to make payments, either locally or internationally.

The technologically advanced era has resulted in the development and growth of the smartphone applications, especially the ones dealing with payments. These have collectively been observed to have skyrocketed during the past few years, since the consumers consider these to be highly convenient as they can access and make payments within a matter of minutes [12]. This is even evident from the rise of smartphone applications by banks, which allows the users to make payments by securely logging into the application, in addition to the provision other helpful functionalities to keep the consumes interest and motivated to use these applications. On the other hand, it has also been identified that banks and other financial institutions have shown greater attention towards the enhancement of user experience [13], which they are trying to achieve by making their digital payment systems more flexible in nature, in addition to agility and accuracy.

Though, this trend during its initial years received somewhat of little attention given its lack of value-addition, the financial institutions have now transformed these systems by making them more attractive through the inclusion of efficiency and effectiveness [14]. Banks, in the recent years, have invested millions and billions of dollars in their mobile technology, and have ensured that it remains the epicentre of their marketing and promotional activities. This is to ensure that the young consumers, who have previously ignored this trend, can understand the importance in the future, especially the value of the future digital payments. Since the younger generations are more interested in compensations and rewards, financial institutions have further added these aspects into their digital payment methods [15], so that the consumers would more likely to adopt and use the innovative and advanced digital payment methods.

\section{DISCUSSION}

The literature has identified some of the most instrumental trends observed in the technologically advanced era, but these have also identified some of the considerations that must be taken into account to optimally meet the changing demands and needs of the consumers, especially when they are considering digital payments [16]. The first consideration to be taken into account is in the form of increasing the security of the payment system, since this is the only way of keeping the customers, across the globe, to remain motivated and attracted, since these security features can protect them from fraudulent activities. If this consideration is specifically taken into account of Virie Escrow payment, it can be identified that this payment method has facilitated transactions, while ensuring that the interest of the parties - both customers and buyers - can be safeguarded [2-4]. The Virie Escrow services have offered the consumers with a reliable platform which allows for the exchange of monies as well as documents. However, when Virie escrow is being discussed, it is always important to consider its competitors as well, which are in the form of deposify, WeGoLook and Armor. All of these directly compete with Virie Escrow, but the only factor that differentiates this system with others is its security features, which are better than those of its competitors. This is somewhat identified to be a critical success factor of the digital payment platforms, and more specifically, it has been reflected that only those digital platforms can succeed in the 21 st century that offers increased simplicity, in addition to the accuracy as desired by the consumers [17].

For a digital payment system, it is exceptionally important to consider several aspects given the evolving payment economics. In this context, it has been suggested that upmost importance should remain on the provision of the core financial services, while moving away from the traditional payment practices to more advanced payment-related capabilities so that the demands of the users and consumers can be effectively met [18]. Though, the trends related to digital payment have created opportunities for the generation of revenues, in addition to the disintermediation of the competitors, it can also help in creating the needs with respect to the streamlining of the organisational responsibilities as well as the updated governance models. All of these can collectively help in enhancing the speed of the digital payment systems and markets in the delivery of all of the capabilities. However, this can only be achieved through the redesigning of the organisational practices and processes, as well as the technologies that may lead to greater alignment; thereby resulting in improved customer experience [17-19]. These can even help in enhancing the continuity of the plans to work on and develop the digital and physical infrastructure; meanwhile opening opportunities through which compliance with regulations and standards can be maintained. This consideration can help the digital payment systems in driving greater processing simplifications; thereby leading to improved engagement of the consumers.

The technological advancement has offered equal opportunities to the new and incumbent players in the payment processing industry, and has even helped them in the launch of their innovative and technologically advanced products and services through which the consumers can be attracted to these platforms, given the fact that these can establish creative experience. However, this is only possible when digital payment services are based on competitive pricing. There are plethoras of examples that have failed because of their services being offered are premium prices; though these were innovative and creative in nature, but since these were at higher prices, these were avoided by the consumers [20]. This means that the future digital payment services must be based on competitive pricing, which can help to make strategic positioning choice; thereby resulting in improved ability to compete. This can be critical for the digital payment markets and systems, since there is a growing and ever-increasing appetite for the technologicallyadvanced and innovative payment solutions.

When digital payment is being discussed, it is always important to take account of the customer experience, which has been acknowledged to be critical given the universal 
expansion of the payments, which has made customer experience among the prime competitive differentiator in the industry [16]. During the 21st century, the experience of the consumers has reached a completely new stage, which has been acknowledged to be frictionless and invisible with respect to payments. This can be presented a major shift, when compared with the past, since previously it was either through consumers visiting stores or online shipping. However, now the consumers can engage in embedded and invisible payments, which have led to the experiences to become blended [15]. In majority of the instances, the consumers have been provided with the opportunity to automatically pay through the platforms like escrow, which protects the buyers and sellers, while keeping the entire experience focused on security - rather than the payment. Rather than keeping the information on file, the digital payment systems have stored the information with optimal level of security, which has helped in resolving the issues revolving around security breaches. These systems can ultimately make the traditional payments systems to almost disappear, since these digital payments can be embedded into applications [14-17]. This can enable multiple industries, which are generally less payment-oriented to focus greatly on the incorporation of frictionless payment experiences, especially given the case of consumers trying to pay for goods and services in the international marketplace.

The trend for e-commerce payment has been continually rising with the passage of time, and it has been cited that this particular sector accounts for approximately 1/6th of the total global retail sales during 2019, while being forecasted to increase by 20 per cent on annual basis. Though, it is extremely difficult in becoming a global retailer because of the obstacles in the form of international payment processing in addition to the prevention of frauds [18]. This is the reason that businesses have avoided selling across borders; however, this has eventually affected them given the fact that these businesses are clearly missing out on enormous opportunities. Yet, there are opportunities in the form of escrow payment, which can surely help the companies in becoming global retailers, since the customers and sellers would be protected, even their payment. The payment will remain with the escrow until the demands and needs of the customers are met, which means that in case of defected products, escrow can ensure that the buyers are not being paid. This can make digital payment systems to help companies in their strategic objective of establishing cross-border payment alliance through the likes of contemporary payment service providers.

\section{CONCLUSION}

Conclusively, the analysis of the trends and considerations with respect to the digital payment landscape confirmed that there are unprecedented opportunities and benefits that can be taken advantage in the future. One of the most prominent trends was in the form of increasing need to focus on user experience, which if embraced by the digital payment platforms can result in improved attractiveness and adoption rate by the consumers, especially in the case of cross-border payment system. The report has also identified that increasing security has become a need of the future, and consumers tend to only prefer those digital payment service providers that can assure the security of their cross-border and local payments, in addition to their protection against fraudulent activities.

\section{REFERENCES}

[1] P. Tasca, "Digital currencies: Principles, trends, opportunities, and risks," Trends, Opportunities, and Risks. 2015.

[2] M., Dorofeyev, M., Kosov, V., Ponkratov, A., Masterov, A. Karaev, and M., Vasyunina, "Trends and prospects for the development of blockchain and cryptocurrencies in the digital economy," European Research Studies Journal, 21(3), pp.429-445, 2018.

[3] B.U.I., Khan, R.F., Olanrewaju, A.M., Baba, A.A. Langoo, and S., Assad, "A compendious study of online payment systems: Past developments, present impact, and future considerations," International journal of advanced computer science and applications, 8(5), pp.256-271, 2017.

[4] Y. Thomas, and R., Srinivasan, "Emerging shifts in learning paradigms-from millenials to the digital natives," International Journal of Applied Engineering Research, 11(5), pp.361-3618, 2016.

[5] B., Jiří, "The employees of baby boomers generation, generation X, generation $\mathrm{Y}$ and generation $\mathrm{Z}$ in selected Czech corporations as conceivers of development and competitiveness in their corporation," Journal of Competitiveness, 8(4), pp.105-123, 2016.

[6] Accenture, "Driving the Future of Payments," [Online] Available at: https://www.accenture.com/us-en/insight-banking-future-paymentsten-trends.

[7] H.G. Cho, and H.S., Yang, "A Methodology for the Improvement of Accredited Digital Certificate Integrating FIDO Biometric Technology and TrustZone," Journal of Digital Convergence, 15(8), pp.183-193, 2017.

[8] N., ChitraKiran, B., Teja, S., Suresh, B., Krishna, S.M. Akarsh, and J. Yomas, "A biometric based payment system by using payee and payer module," In 2017 2nd IEEE International Conference on Recent Trends in Electronics, Information \& Communication Technology (RTEICT) (pp. 2252-2256). IEEE, 2017.

[9] J., Stickland, "Where in the world are biometric payments taking off?” Biometric Technology Today, 2018(6), pp.8-10, 2018.

[10] E.M., Redmiles, A.R. Malone, and M.L., Mazurek, "I think they're trying to tell me something: Advice sources and selection for digital security," In 2016 IEEE Symposium on Security and Privacy (SP) (pp. 272-288). IEEE, 2016, May.

[11] J., Pal, P., Chandra, V., Kameswaran, A., Parameshwar, S. Joshi, and A., Johri, "Digital payment and its discontents: Street shops and the Indian government's push for cashless transactions," In Proceedings of the $2018 \mathrm{CHI}$ Conference on Human Factors in Computing Systems (pp. 1-13), 2018, April.

[12] Y., Wang, C. Hahn, and K., Sutrave, "Mobile payment security, threats, and challenges," In 2016 second international conference on mobile and secure services (MobiSecServ) (pp. 1-5). IEEE, 2016, February.

[13] E.D., Matemba, G. Li, and B.J., Maiseli, "Consumers' Stickiness to Mobile Payment Applications: An Empirical Study of WeChat Wallet," Journal of Database Management (JDM), 29(3), pp.43-66, 2018.

[14] J., Sun, Q., Zhong, L., Kou, W., Wang, Q. Da, and Y., Lin, “A lightweight multi-factor mobile user authentication scheme," In IEEE INFOCOM 2018-IEEE Conference on Computer Communications Workshops (INFOCOM WKSHPS) (pp. 831-836). IEEE, 2018, April.

[15] F., Tommasi, C., Catalano, M. Fornaro, and I., Taurino, "Mobile Session Fixation Attack in Micropayment Systems," IEEE Access, 7, pp.41576-41583, 2019.

[16] J., Kang, "Mobile payment in Fintech environment: trends, security challenges, and services," Human-centric Computing and Information Sciences, 8(1), pp.1-16, 2018.

[17] J., Pal, P., Chandra, V., Kameswaran, A., Parameshwar, S. Joshi, and A., Johri, "Digital payment and its discontents: Street shops and the Indian government's push for cashless transactions," In Proceedings of the $2018 \mathrm{CHI}$ Conference on Human Factors in Computing Systems (pp. 1-13), 2018, April.

[18] P., Tasca, "Digital currencies: Principles, trends, opportunities, and risks," Trends, Opportunities, and Risks (September 7, 2015), 2015.

[19] E., Taylor, "Mobile payment technologies in retail: a review of potential benefits and risks," International Journal of Retail \& Distribution Management, 2016.

[20] S. Singh, and R., Rana, "Study of consumer perception of digital payment mode," Journal of Internet Banking and Commerce, 22(3), pp.1-14, 2017. 